\title{
WINFRIED WEHLE
}

\section{Literatur als Bewegungsraum. Prousts kinästhetischer Ausgang aus der Krise des modernen Subjekts}

Geht man von der Geschichte aus, die Proust sein erzählendes Ich vortragen lässt, so führt sie es in verschlungenen Wegen, Umwegen, Abwegen durch die selva oscura eines Lebens, hin- und hergerissen zwischen „souffrance“ und „joie“. $\mathrm{Da}$ ist auf der einen Seite das Bedürfnis des Ichs, ihnen als Schriftsteller eine Identität abzugewinnen - seine „vocation“. ${ }^{1}$ Auf der anderen Seite aber lässt es sich dabei von einem Anspruch leiten, den es danach auf denkwürdige Weise annulliert: dass diese literarische Rekonstruktion seinem Lebensstoff ein „sujet philosophique“ im Rang einer „vérité abstraite“ abzugewinnen habe². Proust inszeniert hier eigentlich ein Problem, das er in seiner Vorstudie zur Recherche, in Contre Sainte-Bewve, bereits verworfen hatte. ${ }^{3} \mathrm{Als}$ Wiederaufnahme wird es hier aber gerade als notwendige Voraussetzung in Zusammenhang gebracht mit dem Gelingen seiner Recherche. Vom Anfang zum Ende vollzieht sich so ein Prozess, in dem sich exemplarisch die Ablösung einer zweiten von einer ersten Moderne ereignet. Die Recherche gibt sich dabei als ein grundsätzlicher Discours de la méthode zu erkennen. Zwar äußert sie sich nicht so lauthals, ungestüm und provokativ wie die umgebenden Avantgarden. Wie jedoch ihre Anziehungskraft gerade auf systematisch denkende Köpfe des 20. Jahrhunderts zeigt, hat sie nachhaltig eine grundlegende Umwertung der Zeit sprachmächtig werden lassen. Sie besagt, dass die Zeit von positivistischen wie idealistischen Anleitungen des Denkens um ist. Die Dekadenz ist voll von deren Abgesängen. Wie soll man fortan „connaitre l'homme“, eine Frage, die Proust aus Contre Sainte-Benve übernommen hat?4 Sie kann jedenfalls nicht länger philosophisch, sie muss ästhetisch aufgeworfen werden. Anders gesagt: Zuständig für Philosophie in der Zweiten Moderne wäre Kunst.

Am langen Schreibweg der „Recherche“ mag zu ermessen sein, wie viel Tradition dabei zu überwinden war. Der Aufwand hat sich in einer Reihe von intellektuellen Vatermorden niedergeschlagen. Neben Sainte-Beuve traf es auch Mallarmé, Ruskin und manch anderen seiner Pastiches. Im Grunde gilt dies selbst für Henri Bergson. Wer dessen Essais sur les données immédiates de la conscience zusammen mit der Recherche liest, erkennt, wie intensiv Proust sich anknüpfendabwendend auf ihn bezieht. Zwar verwirft auch Bergsons lebensphilosophische

1 Marcel Proust, À la Recherche du temps perdu, 4 Bde., hrsg. v. Jean-Yves Tadié, Paris 1987-89, im Folgenden RTP I - RTP IV, hier RTP IV, S. 478.

2 RTP I, S. 176.

3 Marcel Proust, Contre Sainte-Bewve, hrsg. v. Pierre Clarac und Yves Sandre, Paris 1971, S. 211 ff. In der Folge zitiert als CSB.

4 CSB, S. 220. 
Kritik die Lebensbegriffe des 19. Jahrhunderts als uneigentlich. In letzter Konsequenz bleibt er aber noch immer einem erweiterten Begriff von philosophischer Wissenschaftlichkeit verpflichtet: „l'intelligence reste le noyau lumineux autour duquel l'instinct $[\ldots]$ ne forme qu'une nébulosité vague“ - um sich im gleichen Atemzug dennoch das Defizitäre dieser Selbstverpflichtung einzugestehen: „L'intention de la vie, le mouvement simple qui court à travers les lignes, qui lie les unes aux autres et leur donne une signification, lui [i.e. à l'intelligence] échappe“. 5 Und dann formuliert er einen Satz, der ihn nicht nur gleichsam selbst überwindet, sondern zugleich eine Recherche ins Auge fasst, die im Grunde nichts Geringeres als das Schreibprojekt Prousts umreißt: „C'est cette intention que l'artiste vise à ressaisir en se plaçant à l'intérieur de l'objet par une espèce de sympathie, en abaissant [...] la barrière que l'espace interpose entre lui et le modèle [i.e. l'objet]". ${ }^{\circ}$

Früh bezieht Proust genau in diesem Sinne Position. Bereits die Préface zu Contre Sainte-Beuve hatte Bergsons psychologische Erkenntnislehre aufgenommen - um sie radikal zu vollenden: „l'intelligence ne mérite pas la couronne suprême [...]; l'instinct doit occuper la première place ${ }^{6 \sigma_{7}}$. Worauf stützt sich Prousts kapitale Umwertung der traditionellen Wertehierarchie? Für seinen Roman war sie, auch im wissenschaftlichen Sinne des Wortes, keine Frage der Anwendung mehr, sondern einer Recherche. Zumal vom Ende her gesehen erscheint der Anfang des Romans wie die Eröffnung einer phänomenologischen Reduktion in dieser Absicht. Ausgangspunkt ist ein Ich, allein, in einem allenfalls schemenhaften Raum, so gut wie situationslos, das seinen Erinnerungen nachgeht. Gänzlich ausgeblendet ist die Stadt, in der man das Ich biographisch situieren darf. Draußen ist Bewegung, die erst - raumsymbolisch - drinnen als bewegend empfunden wird; eine der Grunderfahrungen von La Prisonnière. Am Ende ist das Ich wieder in einem konturlosen Zimmer, aber jetzt, um schreibend festzuhalten, was es erinnernd in Erfahrung gebracht hat. Proust hat lange um diesen Eingang gerungen ${ }^{8}$. Insofern ist er programmatisch ausgezeichnet. Wenn das Ich sich erzählend vergegenwärtigt, wie es sich früher dem Einschlafen und Aufwachen hingegeben hatte, dann um sich jetzt die Bedeutung dieser Schwelle bewusst zu machen. Eingelassen ist diese Ursprungsszene des Romans in einen Hell-Dunkel-Kontrast.

5 Henri Bergson, Euvres, hrsg. v. André Robinet und Henri Gouhier, Paris ${ }^{31970, ~ S . ~ 645 . ~ I n ~ d e r ~}$ Folge zitiert als $B$.

6 Bereits in seinem ersten Werk, Essais sur les données immédiates hatte er gleichsam das Konzept einer künftigen Kunst umrissen: „Que si maintenant quelque romancier hardi, déchirant la toile habilement tissée de notre moi conventionnel, nous montre sous cette logique apparente une absurdité fondamentale [...], nous le louons de nous avoir mieux connus que nous ne nous connaissons nous-mêmes (B, S. 88). - Proust selbst aus der Gegenperspektive: „,nous avons peine à croire que la science [...], puisqu'il n'y a pas de science que du général, puisse jamais se confondre avec l'art qui a pour mission $[. .$.$] ce particulier, cet individuel, que les synthèses de la$ science laissent échapper" (CSB, S. 495).

CSB, S. 63.

8 Vgl. Winfried Wehle, „In der Arche Noah der Kunst. Prousts Roman als Recherche“, in: Proustiana XXIII (2005), S. 9-43 mit den entsprechenden Belegen. 
Ganz offensichtlich sucht sich das Ich der therapeutischen Entlastung der Dunkelheit zu vergewissern - während es selbst, im Umkehrschluss, sich im belastenden Zustand der Helligkeit befindet. Der Wortlaut des Textes stattet diese Szene sogleich mit traditionsschweren Symbolwerten aus: Das Ich weiß sich im Lichte des Verstandes („esprit“); da es sich der Dunkelheit anzuvertrauen sucht, ist das helle Bewusstsein, der Verstand das Problem. Offenbar vermag nur diese dunkle Art der Wahrnehmung eine Denkweise zu suspendieren, die nach Ursachen fragt und verstehen will („cause“; „compréhensible ${ }^{\text {cc9}_{9}}$ ).

Dies scheint nicht das geringste Indiz für eine kritische Wendung gegen rationalistische Bearbeitungen unserer Wahrnehmungen. Warum aber seine Geschichte von einem geschlossenen Raum ausgehen lassen? Proust nimmt damit bildlich eine heftige Debatte auf, die die herrschende Anschauung von Raum grundlegend in Frage stellt, aber die positivistische Begründbarkeit einer „vérité logique" ${ }^{10}$ meint. George Henry Lewes hatte sie mit Problems of Life and Mind ${ }^{11}$ in Zweifel gezogen. Ernst Mach ${ }^{12}$ hat sie von der Seite physischer Psychologie unterlaufen; Georg Simmel gesellschaftstheoretisch ${ }^{13}$; Edmund Husserl phänomenologisch ${ }^{14}$; Bergson lebensphilosophisch ${ }^{15}$ u.a. ${ }^{16}$ In diesen Kontext tritt auch Proust ein. Seine Auslassungen im Schlussteil Le Temps retrouvé führen nur explikativ aus, was bereits im Anfang, einer japanischen Papierblume gleich, bildlich angezeigt wird. Der methodische Zweifel hatte einen gemeinsamen Nenner: dass Raum nicht objektiv gegeben, sondern subjektiv, im Verhältnis zum eigenen Körper und seinen Bewegungen gemacht wird. Wie kam es zu der irrigen Auffassung? Weil man die Wirkung für die Ursache hielt. Die Diskussion der Zeit hat, verkürzt gesagt, das Verhältnis richtig gestellt, das heißt umgekehrt. Jetzt gilt: Die sinnlichen Wahrnehmungen bieten nur das perzeptive Rohmaterial, aus dem die Räume sind ${ }^{17}$. Was sie uns unsprachlich, ungeistig, afferent mitteilen, wird doppelt, nach den anthropologischen Registern von Intellekt und Instinkt verzeichnet und in eigenen Gedächtnisorten abgelegt: in den beiden „mémoires“ Prousts.

RTP I, S. 3

10 RTP IV, S. 458

11 G. H. Lewes, Problems of Life and Mind, seit 1870.

12 Ernst Mach, „Eine biologisch-teleologische Betrachtung über den Raum“ (1903), in: ders., Die Analyse der Empfindungen und das Verbältnis des Physischen zum Psychischen, Darmstadt 1985, S. $148-160$.

13 Georg Simmel, „Soziologie des Raumes“, in: Georg-Simmel-Gesamtausgabe VII, hrsg. v. Rüdiger Kramme et al., Frankfurt a.M. 1995, S. 132-183.

14 Edmund Husserl, Ding und Raum. Vorlesungen (1907), hrsg. v. Ulrich Claesges, Berlin 1973.

15 Henri Bergson, Essai sur les données immédiates de la conscience (Zeit und Freibeit 1889), Hamburg 32006.

16 Eine Diskussion, die seither kulturwissenschaftliche Fragestellungen bestimmt. Vgl. etwa Dagmar Reichhardt (Hrsg.), Räumliches Denken, Zürich 1996; Wolfgang Kaschuba, Die Überwindung der Distan₹: Zeit und Raum in der europäischen Moderne, Frankfurt a.M. 2004; Jörg Dünne/Stephan Günzel (Hrsg.), Raumtheorie. Grundlagentexte aus Philosophie und Kulturwissenschaften, Frankfurt a.M. 2006; Kathrin Dennerlein, Narratologie des Raumes, Berlin 2009.

17 Vgl. allg. Michaela Ott, „Raum. Ein heteronomisierender Relationsbegriff“, in: Karlheinz Barck et al. (Hrsg.), Ästhetische Grundbegriffe V, Stuttgart 2003, S. 113-149. 
Das Verstandesvermögen entnimmt den Sinnesdaten das, was sich allgemein durchhält, das Gleichbleibend-Konstante, Typen- und Gattungshafte und setzt es in Beziehung zu dem, was es schon weiß, und identifiziert so Begriffsräume der praktischen Vernunft. Nicht die geringste Rolle spielt dabei deren sprachliche Fixierung. Ein Name etwa legt jemanden auf ein Format fest, das ihn über alle Wandlungen eines Lebens hinweg festhält. Der „Bal de têtes“ auf der Matinée de Guermantes entlarvt diese Vorurteilsstruktur unnachsichtig als „représentations spatiales“"18. Sie können eine Persönlichkeit nur simulieren, weil hinter ihnen kein bindendes Original steht. Proust geht sogar soweit, der Realität selbst diesen Scheincharakter zu unterstellen: „la réalité ne se forme que dans la mémoire [i.e. de l'intelligence] "'19 und das heißt, nach ihren - habituellen - Kriterien. Andererseits formt sie ein Ich nach Bildern, mit denen andere auf mich reagieren: Fremdeigenbestimmung. Proust: „notre personnalité sociale est une création de la pensée des autres“ - also ebenfalls ein ,,acte intellectuel ${ }^{\text {“20 }}$ in seinem Sinne. Ich und der andere sind mithin psychophysische Projektionsräume, die wir mit der Festigkeit einer ,notion immobile“ ${ }^{61}$ ausstatten, wie sie im Umlauf sind.

Unter diesem Aspekt betrachtet, weist der Verstand also unsere sinnlichen Wahrnehmungen in seine Speicherplätze ein. Sie gehorchen, wie Proust sagt, den „nécessités de la vie“22. Dem steht deren ganz anders geartete Verarbeitung durch den Instinkt, das Begehrungsvermögen gegenüber. Es reagiert nicht denkend, sondern empfindend auf sie, sucht in ihrer Vielfalt nicht die Einheit, sondern das Einmalige des Eindrucks (,impression“2 $\left.{ }^{23}\right) .{ }^{24}$ Es registriert mithin nicht, was über den Moment hinaus einer stabilen Identität zuarbeitet, sondern was einen momentan - zutiefst - bewegt. „Excitation“ ist, nach Bergson ${ }^{25}$ und Proust ${ }^{26}$, sein Erkennungsmerkmal. Sie wiederum setzt die Imagination in Bewegung, „seul organe pour jouir de la beauté ${ }^{\prime 27}$. Das Madeleine-Ereignis oder das der Kirchtürme von Martinville haben es erzählend umgesetzt. Sie sprechen das Ich, sonst im sedimentierten Zustand des Intellekts, nicht mit den Begriffen von anderen, sondern mit höchst individuellen Eindrücken an. Gewiss, es sind „instantanés“, sprachliche Momentaufnahmen, wie Proust sie nennt ${ }^{28}$, Inbegriffe für die Flüchtigkeit und Vergänglichkeit der Zeit. Eine Erfahrung von Linearität, Kausalität

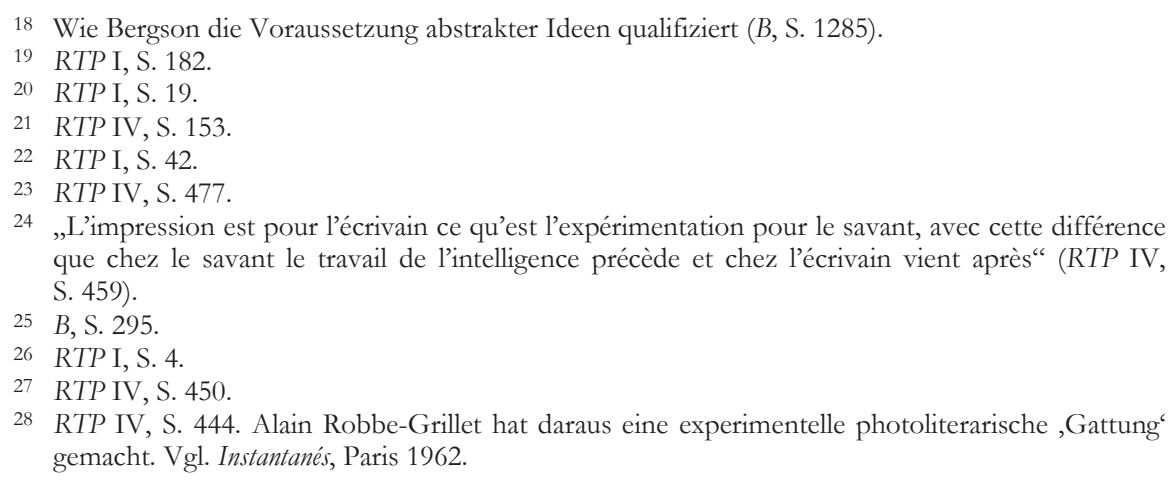


oder Finalität lässt sich daraus nicht mehr ableiten. Als innere Bewegung sind sie für den Verstand unzugänglich: „,tous les efforts de notre intelligence sont inutiles“‘29. Dennoch können auch ihre Sinnesblitze in einem sehr elementaren Sinne Platz finden in einem Gedächtnis eigenen Rechts. Dies vollbringt die berühmt

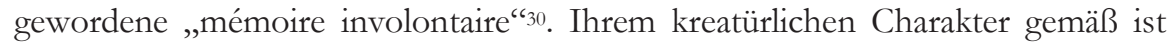
sie „hors de son [i.e. de l'intelligence] domaine et de sa portée“; haben sich niedergeschlagen ,en quelque objet matériel, ${ }^{31}[\ldots]$ dépourvu de valeur intellectuel et ne se rapportant à aucune vérité abstraite “32, verzaubert wie die Prinzessinnen des Märchens. Nur eine gänzlich unmotivierte, absichtslose, weil dingliche Begegnung vermag sie deshalb wieder zu erwecken. Der Verstand würde es als Zufall, Arbitrarität abtun. In surrealistischer Umgebung wird es dann „trouvaille“ heiBen, der Sesam-öffne-dich zu den nächtlichen Depots des Bewusstseins. ${ }^{33}$ Früh schon hatte Proust selbst, im Temps retrouvé, diese unverfügbaren „impressions“ als den Tiefenraum des ,inconscient ${ }^{\star 34}$ identifiziert. Hierhin habe sich „,notre vrai moi“ zurückgezogen. Dessen „Wahrheit“ konnte dem zurückschauenden Ich jedoch nur im Durchgang durch die negative Erkenntnis der „souffrance“"35 aufgehen. Sie hatte ihm instinktiv sein „,falsches Leben“ zu Bewusstsein gebracht: „,nous vivons détourné de nous-même; l'amour-propre, la passion, l'intelligence et l'habitude aussi [...] amassent au-dessus de nos impressions vraies [...] les nomenclatures, les buts pratiques que nous appelons faussement la vie ${ }^{\text {(636 }}$. Dies sind die Folgen eines Denkens, Fühlens und Wollens, das dem praktischen Imperativ des Intellekts unterworfen wurde. Der Angeklagte dieses enteigneten Lebensgefühls („clichés“") 37 ist, über die ganze Recherche hinweg, die „habitude“"38. Um ihrer ,influence anesthésiante“ ${ }^{{ }_{3} 9} \mathrm{zu}$ entkommen, sieht sich das Ich mit einer geradezu paradoxen Herausforderung konfrontiert: mit den Mitteln eben dieser intrumentellen „,intelligence“ und ihren Schutzvorrichtungen der „mémoire volontaire“ zu versuchen, aus den Gemeinplätzen auszubrechen, in die sie sich selbst eingesperrt hat.

Wie wir wissen, ist dies dem erinnernden Ich auf der Matinée de Guermantes auf dramatische Weise gelungen. Den Schlüssel dazu bot ein Wissen über die $\mathrm{Na}$ tur des Menschen, auf das Literatur seit der Moderne der Romantik immer entschiedener eindrang und das Ende des 19. Jahrhunderts wissenschaftlichen Rang

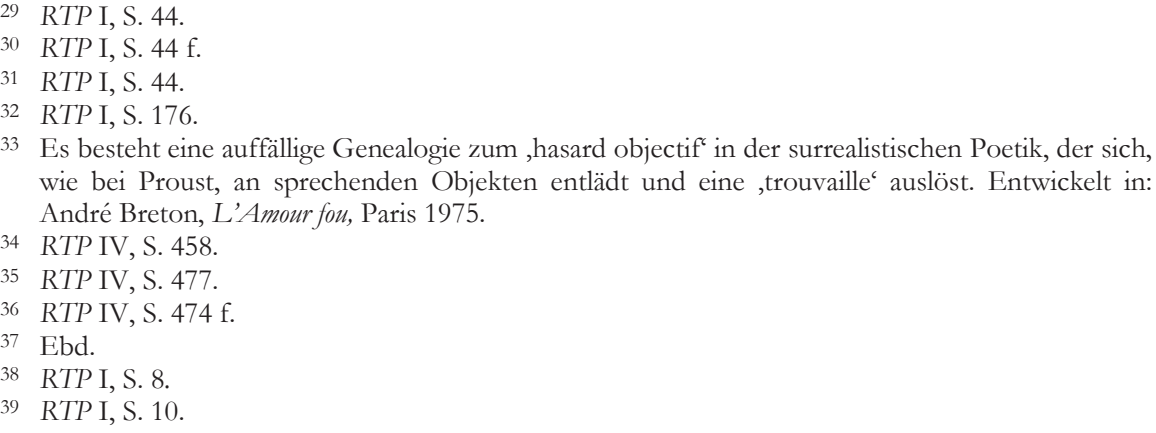

3 Es besteht eine auffällige Genealogie zum ,hasard objectif ${ }^{\circ}$ in der surrealistischen Poetik, der sich, wie bei Proust, an sprechenden Objekten entlädt und eine ,trouvaille‘ auslöst. Entwickelt in: André Breton, L'Amour fou, Paris 1975.

34 RTP IV, S. 458.

35 RTP IV, S. 477

RTP IV, S. $474 \mathrm{f}$

7 Ebd.

RTP I, S. 8.

RTP I, S. 10. 
erlangte: die Kinästhesie, die Lehre von einer vorrationalen, unsprachlichen Bewegungsintelligenz des Körpers. ${ }^{40}$ Sie verdankt sich ihrerseits einem großen Ablösungsprozess. Er hat sich zunächst von der Vorstellung verabschiedet, dass das, was die Welt und, anthropozentrisch, den Menschen im Innersten zusammenhält, transzendent zu garantieren wäre. Literarisch und psychologisch stand dafür lange Zeit der metaphysisch beheimatete Begriff der „âme“. Mit ihm war ein Menschenbild verbunden, das die Natur des Geistes auszuarbeiten hatte. Als jedoch Mallarmé dem Azur abschwor ${ }^{41}$ und Apollinaire Apoll symbolträchtig den Kopf abschlug ${ }^{42}$, war auch von naturwissenschaftlicher Seite längst eine Gegengottheit in Stellung gebracht: Sie hatte ihren Sitz im „corps“. Mit ihm aber war jenes andere Wissen aufgerufen, das sich im „Gedächtnis des Leibes“ (Gehlen) einlagert. ${ }^{43}$ Namentlich medizinische und physiologische Psychologie hatten im Namen von Kinästhesie begonnen, hinter die unwillkürlichen Geheimnisse seiner bioenergetischen Bibliothek zu kommen. Denn je umfassender die Wissenschaften die menschliche Natur nach ihren Gesichtspunkten zubereiteten, desto mehr wurden ihre Anmeldungen aus der Tiefe zum Schweigen gebracht. Ende des 19. Jahrhunderts schien ein Zustand erreicht, den Nietzsche zugespitzt auf diesen Nenner brachte: „[W]ir gehören einer Zeit an, deren Kultur in Gefahr ist, an den Mitteln der Kultur zu Grunde zu gehen“.44 Doch was hat der Rückgang auf den Körper zu diesem Unbehagen in der Kultur (Freud) zu sagen?

40 Die Verwissenschaftlichung dieser neuen Einsichten ging von verschiedensten psychologischen und physiologischen Seiten aus. Um nur einige zu nennen: Henry Charlton Bastian, The Brain as an Organ of Mind, London 1880, auf den Bergson seinen Begriff der ,images kinesthésiques“ mehrfach bezieht (z.B. B 951); Edmund Burke Delabarre, Über Bewegungsempfindungen, Diss. Freiburg 1891; Carl Wernicke, Grundriß der Psychiatrie, Leipzig 1906; Ange Ernest Amédée Ferrand, Le Langage, la parole et les aphasies, Paris 1894. Von dieser Seite her vgl. ergänzend die Bibliographie von Stefano Poggi, „Proust, Bergson und der aphasische Systemkomplex“, in: Ursula LinkHeer/Volker Roloff (Hrsg.), Marcel Proust und die Philosophie, Frankfurt a.M. 1997, bes. S. 171 f. Von der Seite einer „mémoire affective“ her vgl. Paul Sollier, Le Problème de la mémoire, Paris 1900, einer möglichen Inspirationsquelle Prousts, gewürdigt von Philipp Engel/Irene Albers, „Prousts Poetik der ,affektiven Erinnerung: Historische und aktuelle Perspektiven", in: Comparatio 2/2 (2010), S.199-218 (mit weiterer Literatur). - Vgl. allg. auch Jean Starobinski, Kleine Geschichte des Körpergefühls, Konstanz 1987 sowie Alain Berthoz, Le Sens du mouvement, Paris 1997, bes. Kap II. und Carsten Morsch/Christina Lechtermann (Hrsg.), Kunst in Bewegung. Kinästhetische Wabrnebmung und Probehandeln in virtuellen Welten, Bern etc. 2004.

41 Stéphane Mallarmé, „L'Azur“, in: ders., Euvres complètes, hrsg. v. Henry Mondor und Georges Jean-Aubry, Paris 1945, S. 37 f.: „Le Ciel est mort“.

42 Guillaume Apollinaire, „Zone“, in: ders., Euvres poétiques, hrsg. v. Marcel Adéma und Michel Décaudin, Paris 1965, S. 39-44: „Soleil cou coupé“, Anspielung auf Apoll/Apollinaire und seine Grundfigur des ,mal-aiméc.

43 Gewissermaßen als eine Philosophie der Körpersprache aufgenommen und ins Recht gesetzt gegen wissenschaftliche Entwurzelungen der Sprache von Michel Serres, Les Cinq Sens. Philosophie des corps mêlés, Paris 1985, vgl. etwa S. 117 ff. (dt.: Die fünf Sinne. Eine Philosophie der Gemenge und Gemische, Frankfurt a.M. 1998). - Eine andere Rückbindung des Denkens ans Wissen des Leibes schlägt etwa Richard Shusterman von psychosomatischer Seite her vor. Vgl. Performing Life. Aesthetic Alternatives for the End of Arts, Ithaca/London 2000.

44 Friedrich Nietzsche, „Menschliches, Allzumenschliches“, in: ders., Werke, 3 Bde., Bd. 1, hrsg. von Karl Schlechta, Stuttgart 1954, S. 435-1008, hier S. 318. 
Die Eröffnungsszene der Recherche bietet nun genau dazu eine grundlegende narrative Ausführung an. Das erzählende Ich befindet sich im Zustand des kulturellen Sündenfalls, wo „raison“ und „esprit“, die Dinge um uns und damit unsere Gedankengänge immobilisieren: „l'immobilité des choses autour de nous [...] l'immobilité de notre pensée en face d'elles“"45. Ihr Idol, die „certitude“, weist ihnen einen festen Platz zu, der den „nécessités de la vie“ geschuldet ist. Das Ich erinnert sich deshalb an den Jungen, der es damals war und an die Erfahrungen, die er im abgedunkelten Zwischenraum von Wachen und Schlafen gemacht hat. Proust bereitet in dieser Szene nichts Geringeres als eine Flucht aus denen Kategorien vor, in die uns die „mémoire volontaire, la mémoire de l’intelligence “46 einschließt. Außerhalb, unterhalb, in der Welt des Halbschlafs, herrschen umstürzend andere Verhältnisse: Ein „bouleversement [...] complet" ${ }^{\text {“47 }}$ der Wahrnehmung findet statt. Zeit- und Raumordnungen sind außer Kraft gesetzt. Die Eindrücke haben sich aus den festen Stellen losgerissen, die ihnen das Denkvermögen zugewiesen hatte. Nun zirkulieren sie wieder frei und unkontrolliert, einem Kaleidoskop, einer „lanterne magique“ ${ }^{\text {48 }}$, einem „kinétoscope ${ }^{\text {“49 }}$ gleich und leben ihre assoziative Mobilität aus. Dem suchenden Ich scheint es, als ob es sich in einem „Zauberstuhl“ („fauteuil magique“) befände. So ganz außer sich kommt es schließlich auf den Grund dieser Bewegtheit: Jenseits aller verstandesgemäßen Bevormundungen herrscht das Körpergefühl und sein vegetatives Gedächtnis.50 Es vertritt eine schlechthin anti-metaphysische Position: Dem Verstand erscheint es zwar als ein „néant“. Der Instinkt, dem es gehorcht, erkennt darin jedoch ein eigenes, urwüchsiges Prinzip: das „sentiment de l'existence“"51. Es hat, mit Bergson zu sprechen, nichts anderes im Sinn als ,l'attention à la vie“ “52 - mit anderen Worten: ein „memento vitae“, lebhaft leben zu wollen. Der Körper reagiert ständig auf neu eintreffende Sinneswahrnehmungen. Instinktiv weiß er, etwa in Glücks- oder Gefahrensituationen, sofort und unvermittelt, wie er auf einem Stimulus von außen zu antworten hat. Also muss er, so die Grundannahme der Kinästhesie, über ein eigenes, elementares Koordinatensystem verfügen, das blitzschnell seinen Standort zwischen einem Hier und Dort, nah und fern, oben und unten, lebenswichtig und -unwichtig, vor allem aber zwischen beglückend und zerstörerisch zu unterscheiden vermag. Es muss insofern über ein vitales Richtungs- und Raumbewusstsein verfügen, das sozusagen blind seinen Weg kennt. Möglich ist diese kreatürliche Orientierungsleistung jedoch nur, weil der Körper die sensorisch-motorischen Eingaben stets mit früheren Erfahrungen abgleicht, die er in seinem eigenen, bio-logischen Gedächtnis archiviert hat.

\footnotetext{
45 RTP I, S. 6.

4 RTP I, S. 43.

RTP I, S. 5.

8 RTP I, S. 9

RTP I, S. 7.

0 RTP I, S. 6.

1 RTP I, S. 5.

2 B, S. 166.
} 
Hier hat Proust angesetzt. Ihm kommt das überragende Verdienst zu, sich den Beginn seiner großen Recherche mit einer solchen Initiation erschlossen zu haben. Mehr noch: Wie viel ihn dazu auch die zeitgenössische Fachdiskussion angeregt haben mag - das ganz eigene Wissen der Literatur über die menschliche „Seele“ brachte ihn dazu, philosophische und wissenschaftliche Standpunkte und damit auch die Position Bergsons selbst zu überschreiten und den Orientierungssinn der Kinästhesie in einem kinästhetischen „Bewegungsraum“53 nachzubilden dem Roman.

Dazu musste er allerdings zunächst die Frage beantworten, nach welchem Kriterium das Körpergedächtnis sich seine Daten in seine vegetative Topographie ${ }^{54}$ („simplicité première“ ${ }^{{ }^{55} 5}$ ) einträgt. Proust lässt abermals keinen Zweifel: „souffrance“ ist das Siegel dieser phatischen Wahrheitsfindung, das alogische Gegenstück zu Klarheit und Evidenz in der Welt des Intellekts. Alles, was wir leidend in Erfahrung bringen, geht uns deshalb zutiefst etwas an. Doch wie an diese kulturell verschüttete, aber gerade dadurch vital erhaltene „mémoire vraie“ gelangen? Prousts Ansatz ist richtungsweisend. Er lässt das Ich seines Romans einen Weg gehen, der aus seiner Jetztwelt der „habitude“ zurück zu den bewegenden Motiven führt, welche die praktische Vernunft verdunkelt hat. Erste Richtungsentscheidung ist demgemäß, aus der Helligkeit des Verstandes herauszutreten und bewusst der nächtlichen Seite unserer Gedankentätigkeit Raum zu geben. Eine verbürgte Kulturform dieser Rationalismuskritik repräsentiert der Schlaf. Was weiß er mehr als unsere Lebensgewohnheiten? Nicht nur, dass er im Traum alle vernünftigen Schranken überwindet, wie Proust es am Beispiel des lesenden Jungen zu Beginn vorführt. Er vermag auch an das Körpergedächtnis und seinen Orientierungssinn zu appellieren („,mon corps ${ }^{{ }^{656}}$ ). Für Momente durchdringt er den normativen Vorhang der „,habitude“ und lässt frühere Zimmer vorüber ziehen, in denen das Ich geschlafen hat. Sie wiederum geben den Anstoß für die „mémoire (volontaire)“‘57, in den Wachphasen danach sich dieser Räume $\mathrm{zu}$ vergewissern. Und so findet das Ich schließlich zumindest das topographische Gerüst seines Erlebens: Räume; Orte; Combray, Balbec, Paris, Doncières, Venedig, Tansonville. Warum gerade sie? In ihnen sind die wesentlichen Fixpunkte

53 Arnold Gehlen hatte den Begriff in anthropologischer Hinsicht verwendet, ihm aber die Eigenschaften der Kinästhesie zugeschrieben (Der Mensch. Seine Natur und seine Stellung in der Welt, Wiesbaden ${ }^{12} 1978$, S. 175 ff.). Allerdings ging er nicht darauf ein, dass zumal „,moderne“ Künste ihn bewusst in kulturtherapeutischer Absicht einsetzten würden.

54 Die Landschaftstypologie Prousts, namentlich der beiden Wege, die von Combray ausgehen, können als Wegekarte einer inneren Landschaft gelesen werden, die die Dimensionen von Intellekt und Instinkt kartographiert. Zu dieser Betrachtungsweise vgl. Franziska Sick, „Erzählte Karten, Erzählkarten. Morus, Novalis, Goethe, Robbe-Grillet, Gracq“, in: Paul-Gerhard Klumbies et al. (Hrsg.), Raumkonzepte, Göttingen 2009, S. 199-232.

55 RTP I, S. 5.

56 RTP I, S. 6

57 RTP I, S. 9. 
(„point fixe et douloureux ${ }^{{ }^{5} 58}$ ) wie Kreuzwegstationen seiner erotischen Leidensgeschichte festgehalten.

Das erinnernde Ich erfährt dadurch erste Umrisse seines verschütteten Identitätsgebäudes. Jetzt kommt es darauf an, diese Räume, die es von Grund auf so bewegt haben, zu vertiefen. Für den, der aufbrach, das Schreiben zu lernen, hatte sich ein Aufbauschema verheißen. Wer - zumal verlorene - Zeit darstellen will, muss sie, mit einer zeitgenössischen Schrift von Friedrich Ratzel zu sprechen, im Raume lesen.59 Insofern darf die Recherche ein Raumroman genannt werden. War dies aber nicht zeichenhaft unmittelbar in der Eingangszene bereits bedeutet worden, ohne dass das erinnernde Ich es schon begriff, als der in die Nacht hinein lesende Junge in der allerersten seiner träumerischen Verwandlungen sich als „Kirche“ wiederfand, die sich am Ende dann als die Hohlform des Romans erwies, der soeben anhob? Wäre es dabei geblieben, hätte die Recherche vor allem als Gesellschafts-, Sitten- und Dekadenzroman gegolten, vergleichbar den Buddenbrooks von Thomas Mann. Er würde nur den halben Weg auf der Suche nach einer authentischen Selbsterfahrung, jenseits seines anfänglichen „sujet philosophique“ zurückgelegt haben. Von Anfang an war deshalb ein ursprünglicherer Einlass in den „Tresor" vorgesehen, den das Instinktsvermögen verwaltet. Schon Bergson hatte, um seine lebensphilosophische Psychologie schlüssig herzuleiten, eine unterschwellige „mémoire vraie“"60 angesetzt. Wahrhaftig wäre sie, weil dem Zugriff der Vernunft entzogen; wissenschaftlich gerade deshalb unzugänglich, weil an flüchtige, höchst intime Erlebnismomente gebunden. Ihre intensive Präsenz hat jedoch einen hohen Preis: den Verlust von Dauer. Sie gehen mithin dem Zeitbewusstsein verloren - „le temps perdu“. Ihr „processus vital“"61 wahrt jedoch eine verborgene Anwartschaft auf Lebensgestaltung. Als ihr Agent tritt die „mémoire involontaire“ auf. Sie ist Botin dessen, was das Instinktvermögen aufgezeichnet hat. Dieses inkarniert, wie Proust sagt, was ihm wichtig ist, in zufällig beteiligte materielle Objekte. Entsprechend groß muss der Zufall ${ }^{62}$ sein, um auf ein solch unbewusst markiertes Objekt zu stoßen und die daran gebundene Empfindung wieder auferstehen zu lassen (ressusciter63). Plötzlichkeit („soudain“; „,brusque hasard“), Erschütterung („tressaillir"; „ébranler") sind die Kennzeichen

\footnotetext{
58 RTP I, S. 9.

59 Vgl. Friedrich Ratzel, Raum und Zeit in Geographie und Geologie, hrsg. v. Paul Barth, Leipzig 1907 eine wissenschaftstheoretisch geprägte Untersuchung; bes. S. 36 und S. 98 ff. - Im Prinzip von Georges Poulet als einem der elementaren Wahrnehmungsübergänge detailliert nachvollzogen, in dem sich das sprachliche Nacheinander in der Zeit auflöst in „einer kohärenten Pluralität von Bildern“ (S. 109). Vgl. Georges Poulet, Marcel Proust. Zeit und Raum, Frankfurt a.M. 1966. - Vgl. ebenfalls Karl Hölz, Das Thema der Erinnerung bei Marcel Proust, München 1972; bes. Kap II,4: „Die Darstellung der Zeit in der Metaphorik des Raumes" (S. 163 ff.).

60 B, S. 292.

61 B, S. 646.

62 CSB, S. 211

63 Ebd.
} 
dieser ursachlosen Epiphanie, die an die wahre Essenz unseres Selbst zu rühren vermag (,cette essence [...] elle était moi“"64).

Das Modell dieser erlösenden Selbstfindung hat die Madeleine-Episode gestiftet ${ }^{65}$. Der sinnliche Appell, der von diesem Biscuit ausgeht, löst sich gerade nicht in einem Gedanken, sondern in einem ,souvenir visuel“, einer vorrationalen Bildersprache. Dem meditierenden Ich erschließt sich damit nicht nur die Aussicht, wie es wahrhaft zu sich selbst kommen kann. Zugleich ist ihm, ohne dass es dies hier schon zu erfassen vermag, vorgezeichnet, wie diese Erweckung in ein „édifice immense du souvenir“"66 zu überführen wäre: mit einer Poetik des „visuel“, einem metaphorischen Diskurs. Und sinnbildlich steigt aus seinem wieder erweckten Tiefenblick sogleich die Kirche von Combray auf, die Ortsmitte seiner wiedergefundenen Zeit - dunkle Verheißung der Kathedrale im Temps retrouvé, in deren Bildnis schließlich die Suche des Ichs wahrhaft zu sich kommen wird: im „livre“"67. Die Apotheose dieser Epiphanie findet dann auf der Matinée de Guermantes statt. Das Ich braucht diese Kulmination, um seine Glücksgefühle68 sichern zu können: ,je m’efforçais de tâcher de voir clair" ${ }^{\text {“ } 99}$. Mit anderen Worten: um eben die Klarheit der Intelligenz zu Hilfe zu rufen, aus deren Vorherrschaft ihn die „mémoires involontaires“ freigesetzt hatten.

Warum diese Rückumkehr? Das Ich machte auf dem Höhepunkt seiner erfolgreichen Suche nach sich selbst zwei erschütternde Erfahrungen. Was es sich selbst so nahe gebracht hatte, droht sich ihm auf fatale Weise wieder, und dann für immer, zu entziehen. Denn die Wunder seiner Resurrektionen ziehen ein fundamentales Raum-Zeit-Drama nach sich. Zunächst zeitlich: Die aufgedeckte Tiefenidentität schlägt mit solch kinetischer Wucht in der Jetztzeit ein, dass sie alles Gegenwärtige und Vergangene auslöscht und etwas Drittes erzeugt, „beaucoup plus essentiel qu'eux deux“"70, eine Identitätserfahrung ,extra-temporel“, eben „affranchi de l'ordre du temps ${ }^{671}$. Und dann lassen die Eruptionen dieser Kinästhesie einen gewissermaßen intranszendenten Gegenhimmel aufleuchten, wo jeder Todesgedanke geleugnet wird, um, mit Anspielung auf André Gide ${ }^{72}$ ei-

64 RTP I, S. 44.

65 Ebd.

66 RTP I, S. 46.

67 RTP IV, S. 457 f.

68 Ebd.

RTP IV, S. 448.

RTP IV, S. 450.

1 Ebd.

2 André Gide, „Les Nourritures terrestres (1897)“, in: ders., Romans, hrsg. v. Yvonne Davet und Jean-Jacques Thierry, Paris 1958. S. 151-250. - Zumindest im Ansatz eine - erfundene - Autobiographie mit dem Ziel, im Helden (Nathanaël) das „,désir de sortir de soi“ zu personifizieren, um durch eine ,destruction de tout ce qu'il avait appris par la tête“ der wahren Identität auf den Grund zu kommen, d.h. einem bergsonianischen „,'intéresser à la vie“ (!). - Wieviel poetologische Selbstreflektiertheit sich in diesem weiten alimentären Bildfeld niederschlägt, hat Christine Ott offengelegt. Vgl. Feinschmecker und Bücherfresser. Esskultur und literarische Einverleibung als Mythos der Moderne, München 2011, S. 327-459. 
ne himmlische Speise („la céleste nourriture ${ }^{6{ }^{673}}$ ) zu gewähren: leibgebundene Momente der Ewigkeit ${ }^{74}$.

Ihre untergründige Macht erfasst gleichermaßen auch die eingespielten Raumvorstellungen. Sie werden aus der topographischen Ordnung des Gedächtnisses entlassen und in einen Wirbel versetzt, den der „fauteuil magique“ am Anfang befremdlich angekündigt hatte. Räume und Zeiten werden dadurch gegeneinander durchlässig („perméable“675) und geben ihre Logik des Neben- und Nacheinander auf. Drahtlos müsse die Imagination werden (,immaginazione senza fili“) hatte neben Proust der futuristische Aufstand gegen rückwärtsgewandte Kunsttraditionen gefordert. ${ }^{76}$

Doch diese beglückende Zeitlosigkeit und Raumenthebung der „mémoires involontaires" muss, wie alle Paradiese, wunschhaft bleiben. Der Roman schließt mit einer überwältigenden Schreckensvision („effroi géant ${ }^{6677}$ ). Kaum setzt das Bewusstsein ein, macht es sich klar, dass sie, wie schon die Aufwachszenen angekündigt hatten (,pendant quelques secondes ${ }^{6678}$ ), von ihrer Augenblickshaftigkeit gezeichnet sind. Flüchtig seien sie, könnten nur für einen Moment (,pendant un instant ${ }^{6 / 79}$ ), eine Sekunde ${ }^{80}$ die Absperrungen des Gewohnheitsdenkens durchbrechen. Ihnen fehlt gerade, was die „mémoire volontaire“ für sich genommen bedrückend macht - Dauer, Kontinuität, die Festigkeit und Ich-Verhaftung verleihen. Würde es dennoch gelingen, die ekstatischen Momente der Selbsterfahrung zu verstetigen ${ }^{81}$, sähe sich der Wahrnehmende total überwältigt, so dass er das

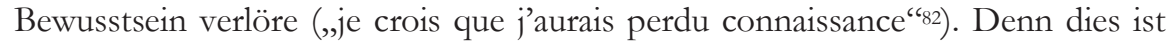
die Kehrseite dieser leibhaften Erkenntnisse: Sie sind an einen sterblichen Körper gebunden. Vergeht seine Materie, erstirbt auch die dort vorgehaltene Essenz des Lebens.

Von daher die beschließende Einsicht des Ich: Die Unterwelt der „mémoire involontaire“ kann zwar nicht an die Stelle der oberflächlichen Welt der „,habitude" treten und sie ablösen. An diesem Traum sind auch die Surrealisten gescheitert. Das Glück der Kinesiologie lässt sich nicht intellektuell festhalten, allenfalls anbahnen, indem es bewusst als unbewusst zugelassen wird. Mehr als einen solchen „rapport“ einzuräumen - Proust lässt sein Ich es mehrfach betonen ${ }^{83}$ - ist nicht möglich, um sein nach-metaphysisches Geheimnis nicht zu zerstören. Nicht ein ganz anderes Leben also, jenseits aller Realität, kann deshalb das Pro-

73 Ebd.

74 RTP IV, S. 454; S. 613.

75 RTP IV, S. 453.

76 Filippo Tommaso Marinetti, „Manifesto tecnico della letteratura futurista (11.5.1912)“; in: ders., Teoria e invenzione futurista, hrsg. v. Luciano de Maria, Milano, ${ }^{1} 1968$, S. 40-48.

77 RTP IV, S. 624

78 RTP I, S. 3

79 RTP IV, S. 455.

RTP IV, S. 613.

1 RTP IV, S. 453.

2 Ebd.

3 RTP IV, S. 468. 
jekt sein, sondern die Revitalisierung des zivilisatorisch verdrängten. Dem Intellekt selbst kommt die Aufgabe zu, dem „élan vital“ des Instinkts Platz zu schaffen in den Einfriedungen der gängigen Nomenklaturen.

Aber wie? Dies betrifft die höchste Implikation der Recherche, die Proust in seinem Roman unternommen hat. Sie steht unter dem Generaltitel einer „vocation littéraire“. Soll sie gelingen, hat sie eine schwerwiegende diskursive Paradoxie zu bewältigen: Einerseits das höchst intime Erlebnis der wiedergefundenen Zeit nicht zu verfälschen. Um es andererseits auf Dauer zu stellen, sieht das Ich keinen anderen Weg als es der Sprache aller, damit aber der anästhesierenden Wirkung der „habitude“ auszuliefern. Verlangt wäre deshalb eine Mitteilungsform, die mit gewöhnlichen Worten einen ungewöhnlichen Gebrauch zu machen versteht. Nur so ließe sich der „élan vital“ erhalten, der die frei nach ihren kreatürlichen Affinitäten sich verschlingenden Erinnerungsbilder bewegt. Das Ich des Romans ist sich des Problems wohl bewusst. Den Schriftsteller nennt es in diesem Sinne „traducteur" ${ }^{\text {"84; }}$ er habe die instinktiven Bekundungen als „équivalents de l'intelligence ${ }^{685}$ zu transkribieren ${ }^{86}$.

Von Anfang der Recherche aber war angelegt, dass diese Sprache Sache der Literatur sein sollte: „La vraie vie, la vie enfin découverte et éclairée, la seule vie par conséquent pleinement vécue, c’est la littérature“687. Der ganze Entwicklungsroman des Ichs spiegelt sich darin wider. Derjenige, der als Leser eines Buches sich träumend ins Bild einer Kirche versetzt sah, begreift jetzt im Bilde einer Kirche das Buch, in dem er sich schreibend aufheben möchte. Eine Art Anagnorisis seiner Berufung zur Sprachkunst hat stattgefunden. Die Stätte aber, wo dem Ich dies schließlich aufgeht, ist, sinnreich genug, die Bibliothek des Hôtel de Guermantes. ${ }^{88}$ Inmitten des sich verausgabenden Stadtlebens von Paris totalisiert sie das Buch ${ }^{89}$ als den Ort, wo sich die flüchtigen „,mémoires volontaires“ angemessen in „équivalents d'intelligence“ anberaumen lassen. Die Matinée de Guermantes offenbart dem Ich dadurch zuletzt, wie die gegenseitig sich befremdenden Interessen von Intellekt und Instinkt auf höherer Ebene, im Raum der Literatur sich begegnen können - wie zuletzt die beiden Wege, die von Combray ausgingen.

Wie sie aber dialogisch, dialektisch zusammenkommen können, das entscheidet sich nicht mehr im Bilde der Bibliothek selbst. Proust hat sich dies in den sakralen Zeichen von Kirche, Tempel und Kathedrale ausgemalt. Sie lassen

RTP IV, S. 469.

RTP IV, S. 621.

86 RTP IV, S. 622. Andernorts verdeutlicht: „Il s'agit de tirer hors de l'inconscient, pour la faire entrer dans le domaine de l'intelligence, mais en tâchant de lui garder sa vie [...], une réalité que la seule lumière de l'intelligence suffirait à détruire“ („Réponse à une enquête“, 1922; CSB, S. 640 f.).

87 RTP IV, S. 474.

88 Als einer der Zentralorte im allgemeinen Rahmen der Frage nach der Raumkonstitution von Angelika Corbineau-Hoffmann gewürdigt. Vgl. „Reflexionen über Räume der Recherche“; in: dies. (Hrsg.), Marcel Proust. Orte und Räume, Frankfurt a.M./Leipzig 2003, S. 7-22.

89 RTP IV, S. 458. 
gleichsam im Sinnlichen ein Übersinnliches erscheinen. Diesen geradezu liturgischen Umgang mit Sprache hat er der Metapher anvertraut ${ }^{90}$. Sie ist das ideale „équivalent d'intelligence“ des Schriftstellers, das „seule peut donner une sorte d'éternité au style ${ }^{\sigma_{91}}$, sein Organonmodell, um es mit einem Begriff des Sprachtheoretikers dieser Zeit, Karl Bühler, zu sagen.92 In ihrem Namen habe, wer ein großer Autor sein wolle, „religieusement“ wiederzugeben, was er den bildlichen Anmeldungen des Instinkts entnommen hat ${ }^{93}$. Prousts Begriff einer solch übertragenen Redeweise geht weit über traditionelle Bestimmungen der Rhetorik und Stilistik hinaus. Ihm bietet sie gewissermaßen einen Veranstaltungsraum, wo sich die Psychomachia zwischen Sinnlichkeit und Verstand unvoreingenommen austragen lässt. Dabei hat Proust die Erkenntnisleistung der Metapher unmittelbar auf die Vollzugsformen der Kinästhesie verpflichtet: Sie arbeite ,ainsi que la vie“69! Von daher die literarische Handlungsanweisung: „l'écrivain prendra deux objets différents“ - gegensätzlich wie Denk- und Begehrungsvermögen - „posera leur rapport $[\ldots]$ et les enfermera dans les anneaux nécessaires“ - in die unumgänglichen „équivalents d'intelligence“ - „d'un beau style ${ }^{(95}$. Solchermaßen verbinden sich zwei sprachliche Zeichen, die, jedes für sich, einerseits denotativ festgelegt, andererseits aber sich gegenseitig fremd sind, sodass sie einen Gegensatzzusammenhang bilden, der auf Auflösung, Synthese, auf ein „,tertium comparationis“ drängt. Sein jederzeit verlockendes Potenzial: Es steht für etwas, das als solches gerade aber unausgesprochen bleiben kann. Proust kehrt jedoch hier im Grunde den herkömmlichen Dienst der Metapher um: Als uneigentlich konnte ihre Rede so lange gelten, wie es noch verbindlich schien, was als eigentlich gelten sollte. Hier, wo die Sprache jedoch dem Instinkt zum Ausdruck zu verhelfen hat, wird ihre Mittelbarkeit gerade zur Botschafterin der Unmittelbarkeit, von der das „moi profond“ weiß. So gesehen ist die Metapher die authentische Sprache des Begehrens.

Allerdings liegt ihr kein rationales, philosophisches oder transzendentes Projekt mehr voraus. Sie soll zwar etwas auslösen, ohne es aber als „Etwas“ einzulösen. Der Titel des Romans versteht sich mithin als Programm: Seine Sprache kann sich nur als Recherche erfüllen; verfolgt damit keinen letzten Sinn, lädt vielmehr zu freibleibender Sinnbildung ein. Sie hat sich von der essentialistischen Frage verabschiedet, „was“ der Mensch sei, um sich - modernistisch - darauf zu konzentrieren, „wie“ seine Identität lebendig zu erhalten wäre. So gesehen ist Prousts Recherche ein „Discours de la méthode“, der der Literatur als Philosophie

90 RTP IV, S. 468. Umfassend historisch untersucht von Roderich Billermann, Die ,métaphore 'bei Marcel Proust, München 2000: „Prousts ,métaphore“ ist das Atom seines Stils“ (S. 255).

91 Wie Proust früh, in Abgrenzung zu Flaubert, seiner eigenen, liquiden` Poetik den Weg bereitet. Vgl. CSB, S. 586.

92 Karl Bühler, Sprachtheorie. Die Darstellungsfunktion der Sprache, Jena 1934, seit etwa 1918 in der Diskussion.

93 RTP IV, S. 472.

94 RTP IV, S. 468.

95 Ebd. 
der Zweiten Moderne den Weg bereitet. Sie geht die instinktive Kommunikation der Kinästhesie ein, indem sie sie in ein vielfältig verknüpfbares metaphorisches Netz übersetzt. Dieser Übergang ist epochal. Proust vollzieht damit, wie die historischen Avantgarden oder die Lebensphilosophie neben ihm, auf seine Weise radikal, die erkenntnistheoretische Wende, die statt in epistemologischer Evidenz nun Wahrheit primär in einer Kultur der Kontingenz und Performanz sucht, wo „l'instinct doit occuper la première [place] ${ }^{696}$. Ein ganz anderer hat dies aus naturwissenschaftlicher Perspektive unterstrichen: der Atomphysiker und Nobelpreisträger Niels Bohr. Er hatte dem Verstand zugestanden, Klarheit zu schaffen; Wahrheit aber davon als nicht-rationale Erkenntnis so unterschieden, dass sie im Grunde mit den kontingenten Anmeldungen des Instinktvermögens kompatibel gemacht werden kann. Sie auszuarbeiten stünde dann auch von dieser Seite der „Wissenschaft" der Künste zu. ${ }^{97}$

Die kinästhetische „Art poétique“, die Proust am Ende von Le Temps retrouvé aufdeckt - sie war längst unausgesprochen präsent. Eine der Pointen der Recherche besteht darin, dass sie die Metaphorologie bereits von Anfang an auf sich angewandt hatte, die sie am Ende dann explizit ausführt. Wenn nicht alles täuscht, hat die berühmte Kutschfahrt um die Kirchtürme von Martinville die Funktion einer verhüllten, aber programmatischen Antizipation (vgl. Textauszug im Anhang) ${ }^{98}$. Nicht nur dass sie auf das erlebende Ich dieselbe berauschende (,ivresse“) Wirkung ausübt wie später das Madeleine-Erlebnis. Mehrfach wird sie in Le Temps retrouvé ausdrücklich als eine Schlüsselszene hervorgehoben ${ }^{99}$. Im übrigen ist sie der einzige Fall, wo ein Erlebnis plötzlich, von einem Augenblick zum anderen, also wie eine „mémoire involontaire“, in Sprache umschlägt (,se formula en mots" ${ }^{\text {"100}}$ ) und für einen Moment den Vorhang hebt (,la vue"), wie das Ich zum Schriftsteller werden könnte. Anderes mehr weist darauf hin, dass diese Episode als große Metapher für die Funktion der Metapher im Proustschen Verständnis stehen soll.

Nicht zufällig findet sie auf dem Rückweg von einer Promenade „du côté de Guermantes“ statt. Deren Verkörperung, Mme de Guermantes, war kurz zuvor als personifiziertes ,,assujettissment aux lois de la vie“"101 vorgestellt worden! Dem Ich erscheint sie deshalb demonstrativ als „forme de l'instinct" ${ }^{“ 102}$. Und die Kutschfahrt führt dann ihr Wesen gleichsam narrativ aus (,apothéose de théât-

96 CSB, S. 216.

97 Auf allgemeine Weise hat Katharina Münchberg dieses erkenntnistheoretische Problem aufgeworfen und mit guten Gründen die Wahrheitsleistung (ästhetischer) Bildlichkeit, durchaus in der Intention Prousts, als Kritik an den Defiziten des philosophischen Diskurses umrissen. Vgl, „Wahrheit und Bild. Zur Kunstphilosophie Heideggers und Derridas“, in: Heinz J. Drügh/Maria Moog-Grünewald (Hrsg.), Behext von Bildern. Ursachen, Funktionen und Perspektiven der textuellen Faszination durch Bilder, Heidelberg 2001, S. 159-176.

98 RTP I, S. 44 ff.

99 RTP IV, S. 184; S. 445; S. 457.

100 RTP I, S. 178.

101 RTP I, S. 173.

102 RTP I, S. 174. 
re“"103). Bemerkenswert: Proust hat die Szene doppelt inszeniert: als erlebt erinnert und schriftlich fixiert, der einzige, damit ausgezeichnete Fall eines Textes im Text. Dadurch soll die Aufmerksamkeit auf die Unterschiede gelenkt werden. Der offensichtlichste betrifft den Kirchturm von Vieuxvicq. Im Fluss der erlebten Erinnerungen wird er einmal wie ein Begleitumstand („séparé") abgesetzt, dann ausgeblendet. Im schriftlichen Nachvollzug allerdings spielt er beständig mit den beiden von Martinville zusammen, sodass sie einen „rapport“ herstellen, der unverkennbar der triadischen Struktur einer metaphorischen Konstellation gleicht. Fundament bilden die beiden Türme von Martinville. Sie werden „technisch" - durch die Kutschenfahrt - in Bewegung versetzt, überspringen aber gerade dadurch ihre lebensweltliche Selbstverständlichkeit, in dem der „technische“ Effekt das poetische Potential anschaulich werden lässt.104 Erhaben (,seuls") setzen sie sich gegen die platte, horizontale Umgebung ab (,perdus en rase campagne"). Bedeutung verleiht ihnen die Vertikale, ihre überragende Richtung himmelwärts. Poetologisch gewendet: Sie stehen für die beiden Terme der Metapher, die zwar vom denotativen Boden der Gemeinsprache ausgehen, in literarischer Verwendung aber konnotativ über sich hinausweisen. Sie sind sich, wie die beiden Türme, zwar nahe, bleiben aber zugleich doch unabhängig voneinander. Was sie verbindet, ist ihr gemeinsamer Fluchtpunkt, der dritte Turm von Vieuxvicq. Sie bilden ein metaphorisches Syntagma. Denn nie fällt Vieuxvicq zuerst in den Blick; stets nur in der Sichtfolge der beiden anderen, als etwas von ihnen Ausgehendes, aber stets auf anderes fortweisend, das sie nur zögernd („,retardataire") einholen (,rejoint"): Er ist ihr „tertium comparationis“. Darauf kommt es an. Denn in unmittelbarer Nähe der Türme von Martinville selbst ist nichts zu erkennen („Vieuxvicq s'écarta“). Dies hatten ihrerseits schon die beiden Türme von Saint-André-des-Champs auf dem Korrespondenzweg der Côté de Méséglise demonstriert ${ }^{105}$. Das unmittelbar Gegebene weiß nur von Naheliegendem. Proust demonstriert es unnachsichtig: „effilés, écaileux, imbriqués d'alvéoles, guillochés, jaunissants et grumeleux“ seien sie, „,comme deux épis“.

Erst als sich die Kutsche wieder in Bewegung setzt, sich also aus Stillstand (,arrêter") und Distanzlosigkeit (,au-devant") löst, beginnt die metaphorische Konstellation der Türme wieder zu sprechen. Dieser bildliche Aufschluss meint Grundsätzliches: In der Nähe der Sprache, auf der Ebene (,plaine“) ihrer „,habitude", gibt es nichts wahrhaft Erhebendes zu erkennen. Sie muss auf Abstand, auf das Niveau uneigentlichen Sprechens angehoben werden. Dennoch: Ein definitives Ziel dieser metaphorischen Anhebung ist damit nicht beabsichtigt; Vieuxvicq selbst wird nie erreicht. Dies wäre „arrêter“. Auf GedankenBeweglichkeit als Wert eigenen Rechts (,nous allions comme le vent“ - der Inspiration?) läuft diese zeichenhafte Kutschfahrt also hinaus. Eine „vérité abstrai-

103 RTP I, S. 173.

104 So die leitende These von Matei Chihaia: „Moderne Lebenswelt im Zeichen der Technik“, in: Patricia Oster/Karlheinz Stierle (Hrsg.), Marcel Proust. Die Legende der Zeiten im Kunstwerk der Erinnerung, Frankfurt a.M. 2007, S. 249-266.

105 RTP I, S. 144. 
te“ zu verfolgen hieße ja, den metaphorischen Aufbruch der statischen „mémoire volontaire“ auszuliefern. Die „wilde“ Kutschfahrt setzt dagegen bildlich den „fauteuil magique“ in Narration um. Die unbeweglichen Objekte, die uns sinnlich begegnen, erscheinen dadurch ständig anders. Metapher, im Sinne Prousts, will mithin Gedankentätigkeit, nicht Erkenntnis generieren. Dies steht in Verbindung mit einer der weit reichendsten Errungenschaften der historischen Avantgarden, namentlich des Kubismus: die Ablösung der Zentralperspektive, der Subjektzentriertheit durch eine Wahrnehmungskunst der Vielansichtigkeit. In ihren Augen ist das Ich ein Pluraletantum; Proust hatte es u.a. an der multiplen Identität von Albertine studiert ${ }^{106}$. Drastisch war es von Pirandello zum Ausdruck gebracht worden: Ich, das ist Einer, keiner, bunderttausend.107

In Windeseile kehrt die Kutsche nach Combray zurück. Mit dem Tageslicht erlöschen auch die wechselnden Konstellationen der Türme. Dass Ich taucht ein in eben die „obscurité" und „nuit“"108, in denen es später sich und sein Kunstwerk erhellen wird. Was hat ihn diese Fahrt Beglückendes (,,je me trouvais si heureux“) wissen lassen? In der schriftlichen Version, und nur in dieser, wird es aufgedeckt. Es sind bezeichnenderweise vier - selbstreflexive - Bilder. Sie bespiegeln jeweils die Trias der metaphorischen Türme metaphorisch. Das erste sieht in ihnen drei zum Aufflug - in übertragene Bedeutungen - bereite Vögel (,trois oiseaux“). Das zweite deutet sie als „trois pivots d'or“, betont damit die funktionale Seite der Metapher: als edler Dreh- und Angelpunkt eines geistigen Bewegungsanstoßes, der mit der Goldfarbe chiffriert auf das Glücksversprechen verweist, das mit der Côté de Guermantes, Venedig und der Kunst verheißen ist. ${ }^{109}$ Der dritte Vergleich steigert die Poesie der Türme zu „trois fleurs peintes sur le ciel“. Sie sind zu Blumen der besonderen Art, zu „flores retorici“ mutiert, die in der Erde der Gemeinsprache gründen, aber im weitesten Sinne in den Gärten des Kunsthimmels („,ciel“) erblühen. Der vierte schließlich erweckt in den drei Türmen „trois filles de légende“ zu mythischem Leben. Sie erscheinen erst bei hereinbrechender, vorzeitlicher Dunkelheit, unter den Bedingungen also, unter denen der alternative Verstand des ,instinct“ zu sprechen beginnt. Bleibt man bei der metaphorischen Deutung der metaphorischen Redeweise, so entsteht aus den steinernen Zeichen der Türme, kraft der im Dunkeln einsetzenden imaginativen - metaphorischen - Unterschreitung realer Ansichten, ein anmutendes Menschenbild, wie die archaischen Tiefen der „Legenden“ es aufbewahren. Spielen die drei Mädchen, in dieser Umgebung, dann nicht auf die drei Grazien an? Als Begleiterinnen der Venus verkörpern sie den Sinn für Schönheit, der in kreatürlicher Sinnlichkeit angelegt ist. Zeugen sie damit nicht für eine Ästhetik, die ihr nach-klassisches, nach-mimetisches Heil in der dunklen Syntax des Begehrungsvermögens sucht?

\footnotetext{
106 RTP IV, S. 125.

1071926 erschienen, aber bereits 1912 konzipiert.

108 RTP I, S. 180.

${ }^{109}$ Dazu Uwe Daube, Dechiffrierung und strukturelle Funktion der Leitmotive in Marcel Prousts ,A A la Recherche du temps perdu", Heidelberg 1963, S. 136 ff.
} 
Proust hat mit den „Clochers de Martinville“ ein funkelndes literarisches Kleinod als „mise en abyme“ seiner kinästhetischen Poetik geschaffen. Demnach erfüllt das Kunstwerk seinen - modernistischen - Auftrag, wenn es die Anmeldungen aus den Verließen der Körper-Sprache in einer ihr gemäßen Umschrift abbildet. Woran sie dabei Maß nehmen kann, hat Proust so erläutert: „la vie [...] tisse sans cesse (des fils) entre les êtres, entre les événements, [...] elle entrecroise ces fils, [...] elle les redouble pour épaissir la trame, si bien qu' [...] un riche réseau de souvenirs ne laisse que le choix des communications“" ${ }^{\prime 110}$. Dieses Gewebe geht, wie später surrealistische Poetik oder Jacques Lacan ${ }^{111}$, davon aus, dass sich bereits das unterschwellige Leben selbst wie ein ständig umgeschriebener Text ereignet. Die Inschrift auf der Oberfläche des Lebens ist in Wahrheit gerade verworren und unleserlich (,grimoire compliqué et fleuri““112). Diese unablässig sich durchdringenden, verschlingenden, sich paarenden, andrängenden, wuchernden Sinneseindrücke, die in der Unterwelt der „,souvenirs involontaires“ ihren Umtrieb haben - sie geben das Modell seiner Schreibweise vor. Ihrem Diktat habe der Schriftsteller zu folgen. Was soviel heißt wie den inneren Text in einen äußeren zu übersetzen, die ,mouvements perpetuels et changeants" ${ }^{\prime \prime 113}$ unseres Tiefen-Ichs in einem schriftlichen Analogon anzuberaumen. Ohne es ausdrücklich zu sagen, äußert sich darin das eigentliche „sujet philosophique“, das Prousts Ich von Anfang an gesucht hat: Wahrheit - über den Menschen - stellt sich erst ein, wenn man ihn nicht in seinem Sein, sondern in seinem Werden sucht. Maurice Blanchot etwa wird dies zu einer bizarren philosophischen Ästhetik ausweiten ${ }^{114}$, die dann bei Foucault, Derrida oder Klossowski und anderen „postmodern" durchschlägt.

Bisher galt es als ästhetische Tugend, sein Kunstwerk tektonisch anzulegen. Proust hingegen überführt es in eine offene Form mit einer rhizomatischen Textur. ${ }^{115}$ Statt einem großen Sinn zuzuarbeiten, richtet es sich gleichsam intransitiv ein, um semantische Kettenreaktionen auszulösen. Sprachlich gesehen stärkt Proust damit das Eigenleben der Signifikanten gegenüber der Vormundschaft der Signifikate. Nur so lässt sich die Bewegungsintelligenz der Kinästhesie ohne erhebliche rationale Abschläge erfahrbar machen. Entsprechend hat sich der Text

110 RTP IV, S. 607.

111 Vgl. Jacques Lacan, Le Séminaire XI. Les quatres concepts fondamentaux de la psychanalyse, Paris 1973, hrsg. v. Jacques-Alain Miller, S. 23 u.ö.

112 RTP IV, S. 457.

113 RTP IV, S. 475

114 Vgl. Maurice Blanchot, L'Espace littéraire, Paris 1955 u.ö.

115 Vieles spricht dafür, dass Gilles Deleuze dieses Konzept einer antiphilosophischen Philosophie (ders./Félix Guattari, Rhizom, dt. Berlin 1977) der libidinösen Diskursbewegung Prousts abgewonnen hat (in: Gilles Deleuze, Proust et les signes, Paris 1964), namentlich da, wo er sich zur Kritik des philosophischen Wahrheitsbegriffs äußert (Proust et les signes, S. 23-35). So wie das Rhizom umschrieben wird, trägt es so gut wie alle Eigenschaften der Proustschen Metapher - und wird doch als alternatives Erkenntnisinstrument strikt zurückgewiesen, um eine philosophische Ontologie der Übergänglichkeit durchzusetzen. Jedenfalls hat das Konzept des Rhizoms erhebliche poststrukturalistische und - moderne Entwicklungshilfe geleistet. 
des Romans in einen „Bewegungsraum“ verwandelt. Auch dies ist eine seiner epochalen Inversionen. Damit emanzipiert er das menschliche Bewusstsein von mythischen Altlasten, idealistischen Schiffbrüchen und Fortschrittswahn. Sein Schriftsteller verrichtet zwar die Arbeit der drei Parzen, die des Lebens Schicksalsfäden spinnen; seine metaphorischen Verknüpfungen stehen jedoch unterm Patronat der drei Grazien und versprechen lust- und glückbringende Befreiung aus den Verstrickungen der „habitude“.

Wirklich ereignen kann sich dies jedoch in letzter Hinsicht erst im Akt der Lektüre.116 Prousts „Discours de la méthode“ hat deshalb auch diese Konsequenz intensiv bedacht. Auf den Kopf gestellt sieht sich dadurch gleichermaßen die traditionelle Rolle des Lesers. Ein literarisches Kunstwerk, wie es die Recherche entwirft - und realisiert hat, werde den Leser zum Leser seiner selbst machen ${ }^{117}$. Es bietet ihm einen ästhetisch geschützten Raum („église“), wo er sein Gewohnheitsleben zu durchbrechen vermag („,ce travail que l'art défera“"118), indem es ihm als mentales Ausland („dépayser““119) zu Bewusstsein kommen kann. Dadurch soll er aus sich herausgehen (,,sortir de nous ${ }^{{ }^{\prime \prime} 120}$ ), um zu sich zu kommen. An diese wahre Identität, Proust betont es immer wieder, rührt nur ein „retour aux profondeurs“'121. Dort ist, was uns wirklich betrifft, in einem „livre intérieur“ festgehalten, das, im Lichte des Verstandes gelesen, nur „signes inconnus“"122 enthält. Der Leser ist damit integral in Prousts umfassende Buchmetaphorik einbezogen.

Wäre dann aber der Akt der Lektüre zuletzt nicht selbst als metaphorische Konstellation aufzufassen? Wer sich auf ein Buch im Sinne Prousts einlässt: Ist er eingangs nicht, wie das erlebende Ich des Romans, befangen in seinen trügerischen („mensonges“) Denkgewohnheiten? Wer liest, bildet dann aber einen „rapport“ zwischen sich und dem Gelesenen, der unter dem selben Gegensatzzusammenhang steht wie die beiden Basiselemente einer Metapher: „car les livres se comportent en cela comme des choses ${ }^{{ }^{\prime} 123}$, die, wie die Madeleine, das versiegelte Buch der „mémoire involontaire“ zu öffnen vermögen, wenn deren Welt der Buchstaben, durch befremdliche Zufallsbegegnungen veranlasst („choc“; „ébranlement ${ }^{\text {“'124}}$, in der verhärteten Identität des Lesenden eine kinästhetische Erweckung seiner verschütteten Eigentlichkeit auslösen. Im Sinne von Prousts Metapher gesprochen: Er erlebt sie als sein tertium comparationis. Was er dabei erfährt, bleibt fraglos sein Privateigentum. Literatur, so verstanden, hat keine Botschaften mehr. Auf die Frage, wie sie unter den Bedingungen einer Zweiten Moderne dem „connaître l’homme“ noch dienen könnte, radikalisiert Proust schließ-

116 Vgl. Volker Roloff, Werk und Lektüre. Zur Literarästhetik von Marcel Proust, Frankfurt a.M. 1984.

117 RTP IV, S. 489; S. 610.

118 RTP IV, S. 475.

119 RTP IV, S. 467.

120 RTP IV, S. 474.

121 RTP IV, S. 475.

122 RTP IV, S. 458.

123 RTP IV, S. 464.

124 RTP IV, S. 491; S. 451. 
lich das „faire voir" Flauberts, nimmt ihm aber alle spekulativen Zumutungen und gibt ihm einen strikt instrumentellen Auftrag: sich als „instrument op-

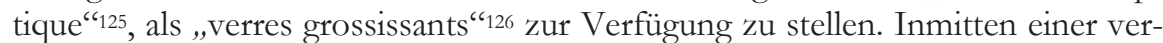
härteten Kultur des Denkens errichtet sie damit einen profanen Sakralbau, wo die Lektüre Anlass geben kann, um in seinem Halbdunkel mit anderen Augen wahrzunehmen, was in einem elementaren Sinn lebendig macht: das „bonheur mobile", wie es an anderer bedeutsamer Stelle, ebenfalls metaphorisch verschlüsselt heiß $\mathrm{t}^{127}$. Wer seine fließende Identität empfangen will, hat sich eben einem kinästhetischen Sprachfluss hinzugeben, der sich unablässig wandelt, um beständig in Einklang zu bleiben mit dem Tiefsten, Flüchtigsten, Geheimnisvollsten in uns. ${ }^{128}$ Das Subjekt, wie es sich seit der Romantik entworfen hat, frei, autonom, selbstbestimmt, weil es glauben konnte, eine Identität sei in ihm selbst garantiert - ihm hat Proust ein Ende bereitet, aber nur, um ihm ein neues Leitbild für wahrhaftes Leben vorzuschlagen. Gegen die erdrückende „travail qu’avaient fait notre amour-propre, notre passion, notre esprit d'imitation, notre intelligence abstraite, nos habitudes" ${ }^{“ 129}$, kann - nur noch - (literarische) Kunst vorgehen ${ }^{130}$, sofern sie die kreatürliche Bewegungsintelligenz aufnimmt und sie in geistige Beweglichkeit überführt und solchermaßen kinästhetische Kulturkritik übt. ${ }^{131}$

125 RTP IV, S. 490.

126 RTP IV, S. 610

127 RTP I, S. 168.

128 Dieses „bonheur“ ist „changeant sans cesse pour rester toujours en accord [...] avec ce qu'il y a de plus profond, de plus fugitif, de plus mystérieux" in uns (RTP I, S. 168).

129 RTP IV, S. 475.

130 Mit bestechender Konsequenz geltend gemacht als Signatur der (Zweiten) Moderne von Helmut Heißenbüttel („Hypothesen über Literatur und Wissenschaft als vergleichende Tätigkeiten“, in: ders., Über Literatur. Aufsätæe, München 1979, S. 195-204), mit den Leitbegriffen „,multiples Subjekt" und „Unauflösbarkeit des Offenbleibenden“".

131 Daran ließe sich auch die Frage anknüpfen, „Wozu (noch) Literaturwissenschaft?“", in: Romanistische Zeitschrift für Literaturgeschicbte 29/2005, S. 411-426. 
Seuls, s'élevant du niveau de la plaine et comme perdus en rase campagne, montaient vers le ciel les deux clochers de Martinville. Bientôt nous en vîmes trois: venant se placer en face d'eux par une volte hardie, un clocher retardataire, celui de Vieuxvicq, les avait rejoints. Les minutes passaient, nous allions vite et pourtant les trois clochers étaient toujours au loin devant nous, comme trois oiseaux posés sur la plaine, immobiles et qu'on distingue au soleil. Puis le clocher de Vieuxvicq s'écarta, prit ses distances, et les clochers de Martinville restèrent seuls, éclairés par la lumière du couchant que même à cette distance, sur leurs pentes, je voyais jouer et sourire. Nous avions été si longs à nous rapprocher d'eux, que je pensais au temps qu'il faudrait encore pour les atteindre quand, tout d'un coup, la voiture ayant tourné, elle nous déposa à leurs pieds; et ils s'étaient jetés si rudement au-devant d'elle, qu'on n'eut que le temps d'arrêter pour ne pas se heurter au porche. Nous poursuivîmes notre route; nous avions déjà quitté Martinville depuis un peu de temps et le village après nous avoir accompagnés quelques secondes avait disparu, que restés seuls à l'horizon à nous regarder fuir, ses clochers et celui de Vieuxvicq agitaient encore en signe d'adieu leurs cimes ensoleillées. Parfois l'un s'effaçait pour que les deux autres pussent nous apercevoir un instant encore; mais la route changea de direction, ils virèrent dans la lumière comme trois pivots d'or et disparurent à mes yeux. Mais, un peu plus tard, comme nous étions déjà près de Combray, le soleil étant maintenant couché, je les aperçus une dernière fois de très loin, qui n'étaient plus que comme trois fleurs peintes sur le ciel au-dessus de la ligne basse des champs. Ils me faisaient penser aussi aux trois jeunes filles d'une légende, abandonnées dans une solitude où tombait déjà l'obscurité ; et tandis que nous nous éloignions au galop, je les vis timidement chercher leur chemin et après quelques gauches trébuchements de leurs nobles silhouettes, se serrer les uns contre les autres, glisser l'un derrière l'autre, ne plus faire sur le ciel encore rose qu'une seule forme noire, charmante et résignée, et s'effacer dans la nuit. [...] $]^{132}$

132 RTP I, S. 44 ff. 
Einsam über die Ebene und wie auf weiter Fläche verloren stiegen die beiden Türme von Martinville zum Himmel empor. Bald sahen wir ihrer drei: mit einer kühnen Wendung sich ihnen gegenüberstellend hatte ein Säumiger, der Kirchturm von Vieuxvicq, sich zu ihnen gesellt. Die Minuten verstrichen, wir fuhren schnell, und dennoch standen die drei Türme immer in der Ferne vor uns wie drei Vögel, die unbeweglich, in der Sonne sichtbar, auf der Ebene hockten. Dann trennte der Turm von Vieuxvicq sich ab, er rückte weiter fort, und die Türme von Martinville blieben allein, bestrahlt vom Licht des Sonnenuntergangs, den ich selbst in dieser Entfernung auf ihren abfallenden Flanken spielen und lächeln sah. Wir hatten lange gebraucht, um ihnen näher zu kommen, so daß ich mir vorstellte, wieviel Zeit es noch dauern würde, bis wir sie erreichten, als auf einmal der Wagen uns nach einer kurzen Wendung uns unmittelbar an ihren Fuß geführt hatte; sie ragten so plötzlich vor uns auf, daß wir mit einem Ruck halten mußten, um nicht ans Portal zu stoßen. Wir setzten unseren Weg wieder fort; wir hatten Martinville schon ein Weilchen verlassen, und das Dorf, das uns noch sekundenlang das Geleit gab, verschwand, als, allein am Horizont stehend und Zeugen unserer Flucht, die beiden Türme und der von Vieuxvicq uns noch ein Lebewohl zuwinkten mit ihren leuchtenden Spitzen. Manchmal trat einer von ihnen zurück, damit die anderen uns noch einmal sehen könnten; doch nun wendete sich der Weg nach einer anderen Richtung, sie kreisten noch einmal im Abendlicht wie drei goldene Stifte und entzogen sich dann meinem Blick. Ein wenig später aber, als wir schon nahe bei Combray waren und die Sonne untergegangen war, sah ich sie ein letztes $\mathrm{Mal}$ in sehr weiter Ferne nur noch wie drei Blumen, aufgemalt auf den Himmel über der flachen Horizontlinie der Felder. Sie erinnerten mich auch an die drei jungen Mädchen in einem Märchen, die in der Einsamkeit zurückgeblieben waren, als es schon dunkelte; und während wir uns im Galopp entfernten, sah ich sie verschüchtert ihren Weg suchen, nach mehrmaligem ungeschickten Straucheln die edlen Silhouetten aneinanderdrängen, die eine hinter die andere gleiten und schließlich auf dem rosigen Himmel nur mehr eine einzige anmutige, in ihr Schicksal ergebene schwarze Gruppe bilden, um dann in der Nacht zu verschwinden. ${ }^{133}$

133 Marcel Proust, Unterwegs zu Swann. Auf der Suche nach der verlorenen Zeit I, übers. von Eva RechelMertens und Luzius Keller, Frankfurt a.M. 2011, S. 264-266. 
